\title{
Study on the Examination Pattern of the Engineering Specialized Courses
}

\author{
Chen Zhao, Yuan-Gang Wang, Jian-Xiao Ma, Ai-Hua Yu \\ College of Civil Engineering, Nanjing Forestry University, Nanjing, P.R.China
}

\begin{abstract}
A comprehensive questionnaire was taken in the faculties and students of engineering subjects. By analyzing the drawback of current engineering specialized course examination, a new pattern of examination is proposed related to contents of examination, methods of examination, types of examination questions and grading standards. The new pattern of examination was tested in typical courses. It is found that the all-process assessing system, open-book and half-open-book examination should be adopted. The scope of examination contents can be broadened. The examination questions should be comprehensive, practice-oriented and openmind. The students' practical ability can be checked by the questions of experiment, design and research. By using the new pattern of examination, the teachers and students would be guided to focus on the ability of comprehensively applying engineering knowledge and analyzing and solving specialized problems.
\end{abstract}

Index Terms: Examination pattern; assessing method; education reform; specialized course; engineering subject

(C) 2012 Published by MECS Publisher. Selection and/or peer review under responsibility of the International Conference on E-Business System and Education Technology

\section{Introduction}

The examination is the main tool for assessing teaching and learning effects in engineering specialized courses. Its goal is to evaluate the students' level of understanding and mastering specialized knowledge and their ability of finding, analyzing and solving problems. However, it is difficult to measure students' real knowledge and ability level with the traditional way of examination, resulting in students' low ability with high scores, rush preparation for exam and low reliability of scores[1,2,3]. With the current examination pattern, the students are put into a passive position and become a knowledge reciting tool, severely limiting their creative and innovative mind[4].

As a result, the universities and colleges in China and abroad are trying to explore scientific and effective methods of examination. The reform in examination methods includes open-book exams, oral exams, composite exams, participatory exams, autonomous exams, case analysis exams, alternative exams, circumstance exams,

\footnotetext{
The study was supported by the Undergraduate Teaching and Learning Reform Program of Nanjing Forestry University (key project No. 2007A07).

* Corresponding author.

E-mail address: czh@njfu.edu.cn
} 
item pools, separation of examination and instruction, etc. These experiments of reform have shown certain innovative patterns in examination[5,6,7].

This study will explore the way, the method and the measure of examination reform for the specialized courses of undergraduate engineering subjects. A new pattern of examination is put forward to enhance the effectiveness and validity of examination as well as the instructing-learning-examining-managing coordination.

\section{Study methods}

The method of questionnaire investigation and survey was adopted in the study. The questioned sample covered university students and faculties in the engineering college of Nanjing Forestry University from 2007 to 2009. Some typical courses were selected to undertake the examination reform.

\subsection{Questionnaire Investigation and Survey}

The investigation and survey is to analyze the goal and the pattern of examination in engineering specialized courses from the views of teachers, students and managing personnel respectively. Various ways and methods of examination were compared and appropriate patterns of examination and appraisal were summarized.

\subsection{Experiment of Examination Reform}

According to the nature of engineering specialized courses and the status of students, the multivariate examination pattern was tested. The pattern covered the contents of exam, the methods of exam, the types of examination questions, the standards of grading, the analysis, summary and feedback of scores. The emphasis was put on the comparative experiment on adaptability and validity of different methods and contents and types of examination questions.

\section{Results and discussions}

\subsection{Questionnaire Investigation and Survey}

\subsubsection{Questionnaire sample}

Over 900 copies of questionnaires were sent out. A total of 761 persons have handed in valid answer sheets, within which $5 \%$ are teachers, $85 \%$ undergraduate students, $8 \%$ graduate students and the left $2 \%$ managing personnel. The specialties cover forest engineering $(8 \%)$, civil engineering $(51 \%)$, traffic engineering $(18 \%)$, engineering management $(2 \%)$, surveying and mapping engineering $(11 \%)$, water supply and sewage engineering $(7 \%)$ and the other majors $(3 \%)$. Table 1 shows the statistics of questionnaire samples. 
Table 1. Statistics of questionnaire samples

\begin{tabular}{lclc}
\hline \multicolumn{2}{c}{ Distribution of Personnel } & \multicolumn{2}{c}{ Distribution of Specialties } \\
\hline \multicolumn{1}{c}{ Status of personnel } & Percentage & \multicolumn{1}{c}{ Specialty } & Percentage \\
Teachers & $5 \%$ & Forest engineering & $8 \%$ \\
Undergraduate students & $85 \%$ & Civil engineering & $51 \%$ \\
Graduate students & $8 \%$ & Traffic engineering & $18 \%$ \\
Managing personnel & $2 \%$ & Engineering management & $2 \%$ \\
& & Surveying and mapping engineering & $11 \%$ \\
& & Water supply and sewage engineering & $7 \%$ \\
& & Others & $3 \%$ \\
\hline
\end{tabular}

\subsubsection{Statistics result of the questionnaire}

a) Attitude towards current patterns of examination: Only $31 \%$ persons feel satisfied with the current pattern of examination while $43 \%$ are not satisfied and $26 \%$ keep an indifferent attitude. $53 \%$ people hope to reform the examination pattern while only $5 \%$ feel unnecessary.

b) Attitude towards the examination methods: Most(89\%) support the all-process assessment in engineering specialized courses. The all-process assessment covers the course attendance, home works, lab experiments, fieldworks, in-course designs, discussions, paper writing, quizes and practical operations.

c) Selection of examination types: $4 \%$ select oral exam and $23 \%$ select written exam while most $(72 \%)$ think it depends on specific conditions. If written examination is adopted, 35\% people prefer close-book, 33\% prefer open-book and the rest $32 \%$ desire half-open-book.

d) Types of examination questions: The types include explanation of terms, comparison of terms, filling in blanks, selection and judgement, definitions, error correction, discrimination, derivation, simple answers, analysis, computation, mapping, photograph description, design, discussion, case analysis, multiple answers, practical operation, etc.

e) Standards of grading: $18 \%$ choose grading according to original scores and $34 \%$ prefer score normalization while $48 \%$ prefer grading by weighting method. $66 \%$ persons prefer scoring on a percentage system and the other $34 \%$ on a ranking base of three to five grades.

f) Appraisal of practice ability: $92 \%$ think it is necessary to assess students' experiment, design and research abilities while only $8 \%$ think unnecessary. The methods of practice ability evaluation are field operations $(77 \%)$ and written descriptions of experiments, designs and researches(23\%).

The statistics result of the questionnaire is shown in Table 2. 
Table 2. Statistics result of questionnaire

\begin{tabular}{|c|c|}
\hline Object Items & Attitude Distribution in Percentage \\
\hline $\begin{array}{l}\text { Current patterns of } \\
\text { examination }\end{array}$ & $31 \%$ satisfied, $43 \%$ unsatisfied, $26 \%$ indifferent \\
\hline $\begin{array}{l}\text { Reform of } \\
\text { examination pattern }\end{array}$ & $53 \%$ necessary, $5 \%$ unnecessary. \\
\hline $\begin{array}{l}\text { All-process } \\
\text { assessment method }\end{array}$ & $89 \%$ preference. \\
\hline Examination type & $\begin{array}{l}4 \% \text { oral exam, } 23 \% \text { written exam, } 72 \% \\
\text { depending. }\end{array}$ \\
\hline $\begin{array}{l}\text { Written } \\
\text { examination }\end{array}$ & $\begin{array}{l}35 \% \text { close-book, } 33 \% \text { open-book, } 32 \% \text { half- } \\
\text { open-book. }\end{array}$ \\
\hline Standard of grading & $\begin{array}{l}18 \% \text { on original score, } 34 \% \text { on score } \\
\text { normalization, } 48 \% \text { on weighting. }\end{array}$ \\
\hline Scoring system & $\begin{array}{l}66 \% \text { percentage system, } 34 \% \text { ranking system of } \\
\text { three to five grades. }\end{array}$ \\
\hline $\begin{array}{l}\text { Appraisal of } \\
\text { practice ability }\end{array}$ & $92 \%$ necessary, $8 \%$ unnecessary. \\
\hline $\begin{array}{l}\text { Methods of practice } \\
\text { ability evaluation }\end{array}$ & $\begin{array}{l}77 \% \text { field operation, } 23 \% \text { written descriptions } \\
\text { of practical operation. }\end{array}$ \\
\hline
\end{tabular}

\subsubsection{Analysis of the questionnaire results}

Most people are not satisfied with the current pattern of examination while one third feel satisfied and one quarter feel indifferent, which indicates the multivariate opinions in the university faculty and students.

The all-process assessment of students' achievement should be adopted in the engineering specialized courses. The all-process assessment should cover students' ordinary performance and examination scores, including home works, experiments, designs, in-class discussions and arguments. The ordinary performance should represent one third of the final score in order to show the students' knowledge and ability level in the specific course.

Both oral and written exams can be used, depending on concrete conditions of the course. In written examination, the open-book and the half-open-book patterns are more adaptive for engineering specialized courses than the close-book pattern. The open-book and the half-open-book patterns would meet the requirements of engineering practices.

The contents of examination can exceed the scope of the course by $5 \%$ to $15 \%$. In this way, the students' knowledge extension can be checked, guiding students to explore frontier knowledge, develop studying interests and train self-study ability.

The practice ability related to the specific course should be tested in order to cultivate students' practice and application awareness. However, on-site tests are not feasible in most courses. A suitable alternative is to give certain examination questions of describing experiments, designs and researches, including equipment operations, working procedures, data analysis, points for attention and matters of regulations.

In the examination, some questions can be appointed as selective topics. Students can choose the questions to answer upon their own preference. In this way, they can give full play to their knowledge and interests, avoiding the same examination contents to all students taking the course.

Finally, it can be found from the questionnaire that the examination in engineering specialized courses should help to cultivate the students' practical knowledge and ability. The examination should be diversified and application oriented. In the examination, the students' ability of acquiring knowledge, analyzing and solving problems should be fully checked. It is necessary to reform the examination pattern in order to lead students to truly enhance their specialized quality and ability. 


\subsection{Experiment Study in Typical Courses}

\subsubsection{Courses experimented for examination reform}

Over ten typical engineering specialized courses were chosen to explore the examination pattern reform during the academic years from 2007 to 2009. The experimented courses included technical courses of civil engineering, specialized courses of forest engineering and road engineering, subject introduction courses, courses on special topics and courses on subject frontier. Some courses were held on a large class base of over 80 attending students, such as Civil Engineering Materials, Science of Traffic Engineering, Construction Organization Planning and Management. Other courses were opened in a small scale of attendees such as Transportation Engineering, Introduction to Forest Engineering, Technology and Management of Timber Production, Introduction to Engineering Environment, Basis of Engineering Machinery and Electricity, Engineering Bidding and Contract Management, Engineering Economics. Over six hundred students had undertaken the reform trial.

\subsubsection{Experiment process}

In the first lesson of each course, the students were shown the goal and the main points of the examination reform in the specific course. The exam and test method, the standards of grading, the requirement of examination and the scope of examination were presented with the contents of the course. During the course, some quizzes, questionnaires and discussions were carried out to find out the attitude of the students, the course progress, the teaching and learning effects. Before the final exam, the types of examination questions, the distribution of contents examined and the scope of contents were further explained to the class. After the final exam, the examination questions and respective scores were analyzed and summarized.

\subsubsection{Analysis of experiment results}

The open-book exams are suitable to courses of strong specialty and practice, which would encourage students to emphasize the comprehension of theoretical knowledge and the combination with practical engineering problems. However, some students may look down on the study and master of basic theory and knowledge in the open-book exam pattern. Thus, as a compromise and balance, a flexible method called halfopen book or "one-page-open-book" method would allow the students to take a piece of self-prepared paper to the examination as an assistance. In this way, the students are pushed to systematically review, sort and summarize the knowledge points of the course while avoiding the mechanical memorizing of the knowledge and concepts.

The examination questions should adopt synthetic questions, topics of application, case analysis, design and computation problems and topic discussions. These types of questions can effectively check the students' understanding and mastering of the specialized knowledge system and the framework of knowledge points, and emphasize the connection and comprehensive application of specialized knowledge.

For some specialized courses with fast development of new knowledge, the examination can lightly exceed the contents in the course specification with the extension under $15 \%$. This would encourage students to keep abreast of new development in the subject, to train self-learning capacity and to build the ability of developing thinking. The broadened contents in the exam would be best designed as open questions such as the hot spots in the subject and the progress of new technology.

The assessment of students' practical ability should be mainly based on the work in laboratories and fieldworks. In written or oral exams, some questions on experiment, design and research description can be set forth to further check the students' understanding of the contents of experiments, designs and researches as well as the instruments applied, operational process, working methods and key techniques related. This is aimed at the practical application of the engineering specialized knowledge. 
Through the experiment of examination reform, most faculties and students approve the new pattern of examination in engineering specialized courses. The new pattern of examination would help to cultivate the practical ability and the creative ability of the students. It is regarded as a good start of examination reform. Further studies and exploration should follow and the effective examination pattern be adopted, resulting in a high quality of specialized education in universities.

\section{Conclusion}

\subsection{The necesity of examination pattern reform:}

With the fast development of higher education in China, it is in urgent demand to reform the pattern of examination in engineering specialized courses. The examination, as a commanding tool to students' learning, should lead the students to pay more attention to the training of practical and creative abilities. A good pattern of examination would promote the learning for practice, reaching the coordination and harmony of teaching, learning, examining and management. It would help to improve the style of study and examination, limiting cheating and fraud in course examination. With a qualified pattern of examination, the examination would fully play a guiding and feedback function in the engineering specialized courses.

\subsection{The direction of examination pattern reform:}

The new pattern of examination in engineering specialized courses should be based on the specific course specification. A scheme of scientific and rational examination should be built. The reform should emphasize the contents of examination, the methods of exam and the standards of grading in order to truly assess the actual knowledge and practical ability of the students. The direction of reform is aimed at avoiding the negative influence of education for examination, high scores with low ability, rash style of study and trend of identical thinking. The reform of examination patterns should lead to the development of creative, applicative, open and diversified human talents.

\subsection{The new pattern of examination:}

The new pattern of examination for engineering specialized courses includes the diversity of examination contents and the multivariate methods of examination. The examination contents should be extended from the basic knowledge, the basic theory and the simple application to the creative thinking, the open knowledge, the comprehensive application and the practical ability. The methods of examination are all-process assessment, open-book and half-open-book exams, proper types of examination questions and grading standards.

\section{References}

[1] R. Y. Cao, "On the structure of the new examination pattern of university courses," Education and Profession[in Chinese], vol. 541, Mar. 2007, pp.182-184.

[2] D. Q. Li, Z. K. Xue, "On new model of the examination system of high learning," Journal of Chongqing Technology and Business University for Social Science[in Chinese], vol. 22, Dec. 2005, pp.134-136.

[3] S. W. Liang, S. Y. Du, L. Y. Wang, Y. J. Zhong, Y. Xie, "Reform the examination system, set up new examination model in colleges and universities," Journal of Chengdu University of Technology for Social Science[in Chinese], vol. 13, June 2005, pp.62-67. 
[4] X. W. Wang, H. Liu, F. Z. Tan, "Reasonable considerations for the examination in the higher education management," Journal of Weifang University[in Chinese], vol. 5, Jan. 2005, pp.52-53.

[5] X. L. Guo, "Countermeasure on reforming course examination system in universities," Journal of Southwest Nationality University for Humanity and Soicial Science[in Chinese], vol. 26, Nov. 2005, pp.384386.

[6] Y. X. Zhang, J. G. Lu, "Study and practice of examination method of engineering mechanics," Higher Education of Science[in Chinese], vol. 62, July 2005, pp.128-129.

[7] W. D. Lawson, "Reliability and validity of FE exam scores for assessment of individual competence, program accreditation,and college performance," Journal of Professional Issues in Engineering Education and Practice, vol. 133, Oct. 2007, pp.320-326. 